\title{
METHODS OF INCREASING THE EFFICIENCY OF SURFACE LINES IN LARGE CITIES
}

\author{
By Williston Fish, \\ Assistant to the President, The Chicago Railways Company, Chicago.
}

When this comparatively new instrument of civilization, the street car, shall have reached its highest degree of efficiency it will transport passengers:

(I) With the highest degree of safety to the passengers on the car and to the public on the street.

(2) With the highest degree of speed consistent with such safety.

(3) With the highest degree of regularity and certainty as to schedule.

(4) With the highest degree of comfort to passengers.

(5) With the highest degree of economy.

Street car service in our large cities, through the labors of an army of able and zealous men, has reached a high degree of excellence, but undoubtedly in each of the points-safety, speed certainty, regularity of schedule, comfort and economy-it is capable of further and perhaps even radical improvements. The question of improvement in the service is one of wide importance. It affects the majority of the people of our large cities daily and twice a day; moreover, the question is not only of great importance now, but it is of growing importance, because the large cities are increasing rapidly in population and still more rapidly in area.

If improvements are practical they will come, and come soon, for we live in the very age of improvement. In the old times there was but a vague, dim notion of what improvements were needed, and little hope or thought that they could be brought about. If people had had horse cars in the year 1000 they would have had the same horse cars in the year 1400 and in the years 1500 , I600 and i700. They might have made changes in the bells on the harness and in the uniforms of the postilions, and on noblemen's cars they would have had banners, armor and gonfalons, but the art of 
street car transportation, as far as transportation itself was concerned, would have had 700 revolving years of "lay-in'-time."

The whole life and development of the street railway is included in a period much short of a century, and we are living in the better end of the period, when progress is growing more and more rapid. Years were required to show that a street car should be a street car and not an omnibus; that the pole on the car should be eliminated; that the driver need not sit on the roof; that front and rear platforms were good things, and that a car in winter should have a heater instead of dirty hay and straw. On the other hand, the last thirty years has seen the rise, development and retirement of the cable car, certainly a great improvement upon the horse car for large cities, and it has seen, also, the rise and development of the electric car to its present state of perfection.

The public now has definite notions of what it wants. It even inquires of itself if it does not want something that it has not yet thought of, and it is broadly awake to its own complete and absolute liberty to go about obtaining what it wants. The result is that specialists in all lines of public service, as well as the administrative and legislative bodies of cities, are not only encouraged, but forced to be constantly on the alert in devising and installing betterments and improvements.

I make this much of an introduction to what I have to say upon two methods of increasing the efficiency of street railways in large cities, so as to assure myself, as well as the readers of this article, that suggested improvements, if they are, in fact, improvements, are worth talking about. If the reacler should consider that the changes suggested here are not, in fact, improvements, that any advantages incident to them are counterbalanced by disadvantages, or that, in the nature of things, they are impossible of accomplishment, that is the end of the matter for him. If, on the contrary, he believes that the changes would on the whole work out advantageously, but imagines that there is an inertia in the public, which makes the suggested changes visionary and impracticable, then let him be sure that he fully appreciates the wonderfully fluent and adaptable times in which we live.

Stops.-The first matter to be considered in this article is whether in large cities the number of stopping points of surface cars can with advantage be diminished. 


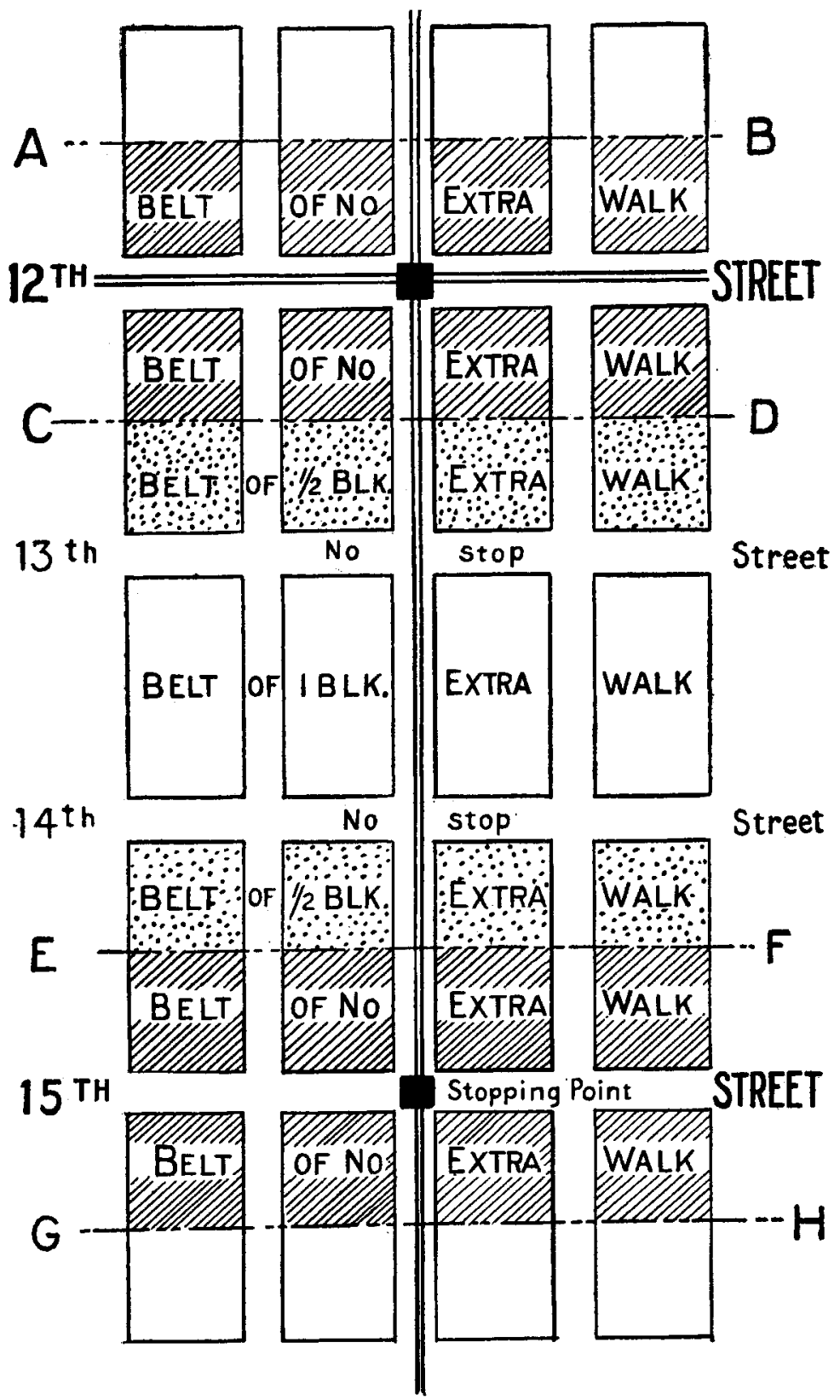


Assume a section of a route as shown on the plat, and consider the stops made by a car in running from north of "I 2 th" street to south of "I5th" street. Under the present practice in our cities the car will stop for passengers to get on or off at any or all of the intersecting streets, so that on any trip the car may stop in succession at "I2th" street, "I 3 th" street, "I 4 th" street and "I 5 th" street.

The question arises then: Is this the system to produce the highest degree of safety, speed, certainty of schedule, and economy? The system, naturally, has a certain effect, small or great, upon each of these factors in street car effectiveness. Conspicuous in its results on important and long routes in large cities, is the intolerable multiplication of stops; but before examining the results of the system, let us first propose a different system; then, witl the two systems before us the results may be studied and compared.

The proposed plan is this: That instead of stopping on signal at "I 12 th" street, "I 3 th" street, " 14 th" street and " I 5 th" street, cars stop only at "I2th" street and "I5th" street, all stops at the two intermediate streets, " 13 th" street and " 14 th" street being entirely eliminated. The system, of course, would not be rigid, but the stopping places would be established so as to include transfer and other important points used by great numbers of street car patrons.

These are the two plans. What are their comparative results upon the great factors of street railway service?

Evidently a disadvantage of the proposed plan would be an increase in the walk of certain passengers. In detail this increase would be :

I. Passengers at " 12 th" street and "I5th" street would still board or leave the cars at these points, and their walk would not be increased at all. These passengers would include all those to and from points between lines $\mathrm{AB}$ and $\mathrm{CD}$ and between the lines $\mathrm{EF}$ and $\mathrm{GH}$.

2. Passengers to or from points between the line $C D$ and

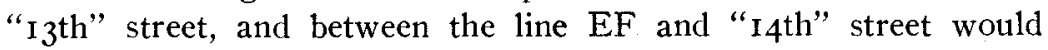
have an extra walk of from nothing up to one block. Assume the average extra walk of these passengers to be one-half block.

3. There remains to be considered the block between "I $3^{\text {th" }}$ and "I4th" streets. Passengers to or from points in this block would have one extra block to walk. They would use either the 
"I2th" street stopping point or the "I5th" street stopping point, as might be more convenient; about half of them would also lose the time required for the car to run a block.

What does the extra walk amount to on the average? If we assume that an equal number of people under the present system use each of the intersections (and this, of course, is a violent assumption, as will hereinafter plainly appear), the result would be that people between the lines $A B$ and $C D$, or one-third of all the people, would have no extra walk; people between the line $C D$ and

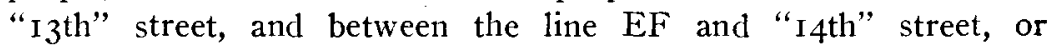
another one-third of the people, would average an extra walk of onehalf a block; people in the middle block, or another one-third of the total, would have an extra walk of one block. The average extra walk for all the people, assuming all present intersections to be now equally used, would therefore be one-half of a block. Under actual conditions, as will be hereafter shown, this extra walk would be about one-quarter of a block.

It is to be particularly noted that although the proposed plan puts the stopping points three blocks apart instead of one block, it increases no passenger's walk more than one block.

As far as I can see, the small extra walk-amounting, in fact, to about one-quarter block for the average passenger, and never rising above one block-is the only disadvantage of the proposed plan. Others may see, perhaps, other disadvantages.

Now, we may consider what the advantages of the proposed plan would be. I believe that in large cities the proposed plan, if installed outside of the most congested district, would result in many advantages, some of them of great value. It is evident that the advantages will vary with the conditions on the route involved. On a route doing a small business, with passengers getting on and off infrequently, the single disadvantage of an average extra walk of onequarter block might exceed the advantages to be derived from the plan. On the other hand, on an important route in a large city, with passengers, under the present plan, making use of a great part of all the intersections for getting on or off, the proposed plan would show its maximum of advantage. If we had a route with one hundred intersections, and there were no street or steam railway crossings, boulevards or other necessary stopping points to break up the regularity of the proposed division into three-block stops, 
such a division would give thirty-four stopping points instead of one hundred; but, although cars may stop at every crossing, in practice they stop only at a certain number of them, and, except by actual observation of a route, it is impossible to say how many actual stops of the car would be eliminated upon that route by establishing the proposed plan. Without a knowledge of the number of stops that would be cut out, it is impossible to say how much time and expense would be saved.

To determine how many stops would be eliminated in actual service, observations have been made upon twelve main lines of street railway in Chicago. Each of the routes observed was carefully examined, and the stopping points which probably would be established, if the proposed plan were used, were determined. It is to be understood that no change was made in the actual operation of the cars, which continued under the present plan of one-block stops. In the theoretical selection of stopping points, a stopping point was included at each strect intersection in the downtown district; outside of this district, a stopping point was supposed at each railway crossing, each steam road crossing, each boulevard, and each elevated station; then other stopping points were supposed intermediate between these necessary stopping points, so that in no case would more than three blocks of ordinary length intervene between stopping points. Good men were placed upon the cars in actual operation under the old system on a route to be observed, with blank books showing, in their order for a round trip, all the present stopping points on the route. The men indicated on the form at what points the car actually stopped, how many passengers got on at each stop and how many passengers got off at each stop. These books, when turned in, were carefully studied and the following table compiled (see page 49 ).

Upon a consideration of this table and the general circumstances of this problem, it appears to me, first, that a change which seems to promise to eliminate 26 per cent of all stops of street cars, except stops caused by traffic blockades, is worth examination, and worth examination now, for, to eliminate 26 per cent of such stops will save much time, increase regularity and certainty of schedules, promote comfort of passengers by reducing stops and starts, and effect important economy in operation by its saving in time, power and wear and tear. 
One block

Number of stopping points for round trip....

Number of proposed stopping points for round trip $\ldots \ldots \ldots \ldots \ldots \ldots \ldots \ldots \ldots$

Number of present stopping points cut out..

Passengers actually counted getting on or off

Of these passengers the number getting on or off at the proposed stopping points was

Number of passengers getting on or off at points that would be disused under the proposed plan $\ldots \ldots \ldots \ldots \ldots \ldots \ldots$.

Number of stops actually made at all points.

Number of stops made at proposed stopping points

Number of stops made at intermediate

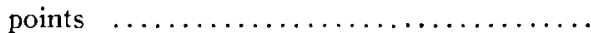

Number of unnecessary stops-that is, stops made to take on or let off passengers within one block of a proposed stopping point on a trip ahen the car actwally stopped at such main stopping point............

Passengers getting on or off at unnecessary stops as defined above, being the 2,146 stops $\ldots \ldots \ldots \ldots \ldots \ldots \ldots \ldots \ldots . . . \ldots \ldots$

Average extra walk entailed on all passengers by substitution of proposed stopping points estimated at about ................. quarter block.

Estimated stops per day on routes observed.

Total unnecessary stops estimated.........

Estimated stops of surface lines in Chicago per day $\ldots \ldots \ldots \ldots \ldots \ldots \ldots \ldots \ldots \ldots \ldots, \mathbf{I , 2 0 0 , 0 0 0}$

Estinated number of stopping points on all surface lines in Chicago for one-way trip,

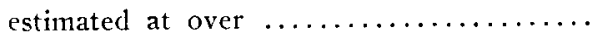

Number of elevated stations in Chicago for one-way trip

$\begin{array}{rrc}\begin{array}{c}\text { Total } \\ \text { for all } \\ 12 \text { routes. } \\ 2,079\end{array} & \begin{array}{c}\text { Average } \\ \text { for } \\ \text { one route. } \\ \text { I73.25 }\end{array} & \begin{array}{c}\text { Per } \\ \text { cent. }\end{array} \\ \begin{array}{r}100.00 \\ 740\end{array} & 61.67 & 35.60 \\ 1,339 & \text { II 1.58 } & 64.40 \\ 19,492 & 1,624.00 & 100.00 \\ 13,280 & 1,107.00 & 68.13\end{array}$

$6,212 \quad 517.00 \quad 31.87$

$6,911 \quad 576.00 \quad 100.00$

$3,853 \quad 321.00 \quad 55.70$

$3,058 \quad 255.00 \quad 44.30$

$2,146 \quad 179.00 \quad 31.05$

$4,290 \quad 357.50 \quad 22.01$

One-

$\begin{array}{lll}199,238 & 16,603.00 & 100.00\end{array}$

$52,948 \quad 4,412.00 \quad 26.57$

7,000

177

Next, it appears to me that the value of the general principle of eliminating intermediate stops is already so amply shown by the experience of urban steam railways and elevated railways, that the public, and especially street railway men, should immediately inquire whether the same principle cannot and should not be applied at once to the street railway; for these urban steam and elevated railways not only attract great numbers of patrons to their far-separated stopping points, but. by the operation of express 
trains, still further reducing the number of stopping points, they are able to draw further large numbers of passengers away from the slower service of their competitors.

That it is not the greater number of stopping points and the reduction of length of walk of patrons that make a line attractive is shown by the fact that in Chicago the elevated roads, with only about 177 s.topping points, haul nearly one-third as many passengers as all the surface lines, with stopping points estimated at over 7000. The elevated roads have a single-track mileage of something over Ioo miles, while the single-track mileage of the surface lines is over $85^{\circ}$ miles; the surface lines give universal transfers; the elevated lines do not, and still, with one-eighth the mileage and onefortieth as many stopping points, the elevated lines attract about one-third as many passengers as the surface lines. Of course, the elevated lines run through what is considered to be the best territory, but they are closely paralleled on both sides by the surface lines. Per running mile, they have about one-sixth as many stopping points as the surface lines. Evidently what the public desires is quick service and regular schedules, and to obtain these it is willing not only to take a longer walk, but even to climb stairs.

I see no particular recommendation of the present one-block stopping system in its genesis. It represents a slight evolution from the early omnibus, which stopped anywhere, but it belongs with the horse car, which moved so slowly that it lost no appreciable time by stopping, and it belongs with the beginnings of our big cities when routes were short. It does not belong in New York, Chicago, Boston, Philadelphia and the other large cities of our present day, and especially not in the larger cities of the future, which will not only contain vast numbers of people, but which also will seek to eliminate congestion in residence districts.

Consider what this one-block system means in a large city. On the Clark street line, in Chicago, in the eight miles between the center of the city and Devon avenue, there are, for a one-way trip, one hundred and thirty points used as stopping places; on the Madison street line, between the downtown district and Fortieth avenue, there are eighty-four stopping points; a three-block system would cut the one hundred and thirty stopping points to forty-seven, and the eighty-four to thirty, still allowing stops at all intersections downtown, and at all necessary points outside. Now, the 
Clark street tracks do not end at Devon avenue, with one hundred and thirty stopping points, but continue six miles further north, making the total number of stopping points on Clark street line alone equal to the whole number of stopping points on all the elevated roads in Chicago; and the Madison street line, after reaching Fortieth avenue, with eighty-four stops, continues on six and onehalf miles further west, and it, too, has as many stopping points as all the elevated railways in Chicago.

\section{Specialization of the Street-car Right of Way}

If it is fine to look into the future and think of the good things that may happen, it is inspiring, on the rare occasions that offer, to anticipate the good things that are bound to happen.

When we plat the population curve of our own city, we may hope that, when it is projected into the future, it will pass through a given point, but we cannot be certain. When, however, we find some desirable point fixed by the equation of a known curve, of which we have already drawn a part, there is a satisfaction in knowing that, when the curve is continued, it will, in spite of the arguments of mistaken people who disagree with us, certainly pass through that point. Evolution of all roads and ways proceeds in accordance with fixed laws, and it is fine to reflect when we ride on a street car, delayed, retarded, impeded, obstructed and blockaded by all the heterogeneous surface traffic of the city, that when the curve of evolution is continued, it is bound to give us unhampered service.

Nature's long course in the establishment and development of channels of distribution and communication in living bodies; and men's etablishment and development of roads move through the same stages; and if, by examining this progress, we can determine the long sweeping curve of evolution of roads and ways, we shall be able with confidence to project it into the future.

In the lowest forms of living organisms there are no channels of distribution or communication. Food and air and sensations travel by diffusion. So, in the lowest forms of society there are no roads.

In considerably higher organisms nature achieves a single definite tube, which is used for all purposes of distribution and in which the matter distributed moves indifferently in either direction. 
So, in the forms of society considerably higher than the lowest, men make trails over which all kinds of traffic move together and indifferently in either direction.

In the highest forms, nature has arrived at different channels for different things; a channel for food, another for air, a set of channels to take blood of the heart and another to bring it in, a channel for the sensation of light and another for the sensation of sound, and so on. So men have produced wagon roads and steam roads and in cities traffic streets, boulevards, elevated roads and subways.

In an infinitude of time, nature has favored a movement from a low to a high efficiency. She has eliminated a great part of friction and other losses of energy. She has worked out channels of distribution and communication, each to do one thing well, instead of several things poorly. Men's progress with roads has been exactly parallel. Nature evolved these successive degrees in the perfection of the distributing system in equal steps with the evolution of the organism as a whole, and man has evolved his roads synchronously with the growth and evolution of the needs of society.

A small organism with few functions to perform has no need for a complicated system of distribution, and, in fact, until this organism is developed in powers of locomotion and means of obtaining ample food, it could not support such a system. So, a small society with few functions to perform could not maintain an elaborate system of roads. As the organism becomes larger, it is evident that distribution by diffusion becomes increasingly difficult and inadequate, and when, to. increase in growth is added increase in activity, requiring the distribution of greater amounts of material for fuel and for the replacement of worn-out parts, the distributing system must be given a corresponding increase in efficiency.

Finally, nature cannot produce the maximum size, activity and efficiency in a living body without a maximum of efficiency in the distributing system in that body, and she cannot produce this maximum of efficiency in the distributing system without arriving at a minimum loss in energy and time. Men cannot produce a city of maximum size and efficiency unless they establish for it, at the same time, the best system of transportation, requiring the least loss of time and energy. We see at once that what sufficed for a small and inactive city will not suffice if we are to have a very large and very active city. 
Now I wish to follow up a little more closely the past evolution of roads and ways in cities, and then suggest for consideration where the curve of this evolution will inevitably lead.

In the earliest villages the roads were common ways, in which pedestrians, horsemen and carts, when the last came into use, moved indiscriminately and in either direction. I find that in the cities of Pompeii and Herculaneum there were narrow embankments, sometimes paved with stone, on each side of the very narrow streets, for the use of foot passengers. Here, of course, was a specialization of a part of the width of the street, but the progress in specialization was not only slow, but intermittent. I undersand that in the early days in London and Paris there were no sidewalks, and as late as I84I a traveler wrote of the streets of Berlin: "They are spacious and long, with broad margins on each side for foot passengers, and a band of plain flagstones on these margins makes them much better to walk on than the streets of most continental cities." In the course of evolution, the width of streets has been increased in correspondence with the increased activity of the people. Streets in the cities of Europe in the Middle Ages were narrow and often tortuous, as are the streets in the sluggish cities of Asia. This type of street may be quite sufficient where the people live and work in their houses, but where there must be general travel toward manufacturing and distributing centers, such streets would be entirely inadequate.

For a time, after.the sides of the roadway in cities had become devoted to the use of foot-passengers, the central roadway was still left unspecialized, and the traffic remaining in it still moved as before.

By another specialization, traffic bound in opposite directions was, to some extent, confined to opposite sides of a street. In some cities, too, they have now proceeded so far that in very busy streets of sufficient width there has been a division between the roadways of rapid vehicles and slow vehicles. By further specialization in some cases there have been developed the boulevard, or pleasure drive, the elevated roadway and the subway.

The long, wide sweep of evolution of the channels of distribution and communication in all of Nature's living organisms, including cities, which are a form of Nature's living organisms, is toward the greatest efficiency, and the components of this efficiency 
are economy in energy, economy in time and capacity for performance of the functions suited to the organism as a whole. In the evolution from small, inactive bodies to large, active bodies, specialization of channels has been one of the prime means of obtaining efficiency.

With the law of evolution of roads and ways in mind, and in mind far more fully and accurately than I have been able to state it, I invite the reader to consider the situation as to street car transportation, and to determine to his own satisfaction the changes that the continued operation of the laws of this evolution will surely produce in it.

When the horse car made its appearance it was simply an omnibus with a fixed track, and owing to the peculiar nature of men, which I do not excuse, the horse car was made to look as much as possible like an omnibus and to obey the rules governing omnibuses. It ran along on the common roadway with the rest of the traffic. Being a horse vehicle, like other vehicles on the street, there was only one new difficulty, and that was, running on a fixed track, it did not have so good an opportunity to proceed as the other vehicles, which could, by ingeniously moving in and out and passing around slower traffic, approximate their own normal rate of progress.

To remedy this inequality, the legislative bodies of cities provided that wagons upon street-car tracks should, on signal, quit the tracks and allow cars to pass. This legislation has been in the city codes in the larger cities of this country for, perhaps, forty years. and, to a certain extent, it has been enforced. In most cases it is our common experience that when the motorman pounds the gong the carload of passengers still look out the front windows and speculate freely as to when the driver of the vehicle ahead will, in fact, leave the track. This is about as far as the evolution of the path of the street car has progressed. Now, what about the further evolution called for by the change from small, inactive cities to large, active cities, by the change in the thing, that is the car, to be moved, and by the requirement of economy in time and energy.

When electricity took the place of animal power, the street car became widely differentiated from all other vehicles on the street. It was more rapid than the most rapid of these other vehicles; it was heavier than the heaviest of them, and, with its load of from twenty-five to seventy-five passengers, consisting in large part of 
the active workers of the city, it became the most important vehicle on the street. Say that the importance of the driver of a traffic wagon, together with his load, is equal to that of two average men, which is an outside estimate, and it is evident that the business of the street car is of much greater importance than that represented by the average wagon. The electric car then is the heaviest, swiftest and most important vehicle upon the street. It has the longest distance to go, and its efficiency in transporting the public rapidly, and in allowing the large cities to expand so as to give all the people ample breathing space, depends upon its speed. When routes were short and the speed of cars was slow, delays caused by slower vehicles running on the tracks ahead of the car were of inconsiderable moment and imposed a comparatively slight tax upon the life of the city.

We have, then, in our large cities, a radically different situation in street car transportation from that in the smaller cities of former times. To show how far different the situation is, suppose that no power-driven car had yet been devised; the working limit of horse car transportation, amounting to some five or six miles, would place a wall around every city within which the city could grow only upon great and disproportionate expenditures of material and vital energy; if to-day our cities of half a million, a million, two millions and four millions were limited to horse car transportation, there would be an immense outcry for a means of faster transportation which would allow the city to grow freely, unconfined and undeformed. By great, good fortune, just as our large cities passed the endurable limits of horse car transportation, the electric car was perfected, capable of almost any degree of speed and of any extent of travel.

The same principles, which, in the past have caused nature and men to specialize channels of distribution, must necessarily now cause a specialization of the roadway of the street car. In the first place, the organism to be served, which is the city, is vastly larger than it was, and its distributing channels must be amplified in proportion. In the second place, we have different things to transmit which must go at different rates and the channels must be specialized.

The earliest steam railroad charters in New England provided that the rails must be designed so as to permit of the operation of ordinary wagons over them. This now seems ridiculous, 
and yet it is ridiculous only on account of the relative speed of steam cars and wagons.

Now, in order to understand the situation, truly we must bear in mind that the present charters of steam railroads eliminate the requirements as to wagon traffic, not because the steam railroads as pieces of property belong to certain groups of individuals, but on account of the service that the public must have from these railroads, considered as channels of distribution, and as belonging to society as a whole. Nobody would want his freight between New York and Chicago to be delayed by traveling along behind a procession of wagons, and when a passenger travels by the steam roads he would be highly dissatisfied if he had to travel behind automobiles going even twenty, thirty or forty miles an hour.

The separation of the several kinds of traffic is a question of relative speed, and when there is frequent passage along a given general course by vehicles, differing greatly in speed, there must be different paths. Except in the most congested parts of our large cities, where possibly at certain times of the day, it may be impracticable, the electric car should be given a clear path. Where streets are paved, wagons should not run longitudinally upon the tracks at all, and they should cross the tracks only at street intersections. I suggest for serious consideration whether, at all street intersections, the street car should not be given the right of way. Steam cars are universally given the right of way at street crossings, and, here again, I wish to point out that this is done because it is inherently necessary in the economy of things. It is done because it would be a comparatively great tax imposed upon society if its heavy, rapid trains of steam cars were obliged to share their right of way at street intersections with other vehicles which are able to stop without much loss of time or energy. The same principle of general economy, which makes it proper that the steam-railroad trains should have the right of way over the electric car at crossings, requires that the electric car should have the right of way over wagons at crossings.

While it will be admitted by every one that a clear right of way for the electric car would be of immense advantage to the public of large cities, the question may arise whether suitable room would be left for other traffic. I think a few words will answer this question. In the first place, if we examine the evolution of roads 
and ways, we will find that the specialization of parts of streets increases the capacity of the whole; even without any such increase there is room enough. For instance, there are 1486 miles of paved streets in Chicago, the average width of which is over sixty-six feet. The street car lines of Chicago are laid upon less than $45^{\circ}$ miles of street. Sidewalks have an average width of over fourteen feet. If then, all of the 1486 miles of paved streets of Chicago were thrown into one street 1486 miles long, and the street cars were given the exclusive use of that part of the sixty-six feet of width proportionate to the total space the tracks now occupy, the entire width of the street would be divided as follows: Sidewalks, twenty-eight feet; wagon roadway between sidewalks and car tracks, thirty-three feet; car tracks, five feet.

Our streets are often called congested; in fact, there is plenty of room upon the streets, except in small territories, and the question is to use the streets so that all the people may derive the greatest advantage from them. All through the twenty-four hours of the day the greater proportion of the street area in the largest cities is practically empty-roadways, sidewalks, and all-and yet in unused streets, even when well paved, car passengers are now obliged to divide the way with wagon traffic. Moreover, it is a fact that, exclusive of the parks, more space is taken up by boulevards in Chicago, mainly devoted to pleasure riding, than is used by all of the street railways in the city.

In conclusion, I wish it understood that I put forth these suggestions for the elimination of stops and for the further specialization of the street car's roadway, for consideration by the public and street railway men. Many good reasons that I have not given for the adoption of these suggestions will occur to them, and perhaps good reasons for not adopting them may suggest themselves. I see that, at present, street-car transportation has not reached an ideal condition. It is not rapid, but slow; the schedules are not regular and certain, but irregular and uncertain; passengers are subject to continuous annoying delays, and the present system is wasteful of time and money. At the same time I see that the history of the street car is but just begun, and from considering its present importance, and the general process of evolution in the contrivances of men, as well as in nature, I am led to trust that many great and important improvements are yet to come. When I see in large cities that it is 
impossible for the public to be given any but a poor, slow and irregular service; if a maximum of stops is made, and if the street-car tracks are used in common by all the street traffic, I am confident that a change will have to be made. People in the largest cities, like people in the smallest towns, have only twenty-four hours a day to live and accomplish their work. When substantial amounts of time are taken from them morning and night in waiting upon transportation, they suffer a direct loss in their efficiency, in what they are able to do, and in the sum of their enjoyments. Their city suffers with them. Restore to the multitudes of people in the large cities who travel by street cars the ten, twenty or thirty minutes twice a day that they lose on account of clogged and obstructed street-car traffic, and you have made almost another race of beings, capable of more work and more enjoyment. When expensive boulevards from 80 to 250 feet in width, surrounding and dividing cities. provided with the best pavement, ornamented with trees and flowers and cared for by gardeners, all at public cost, are considered not too much to devote to pleasure riders, certainly a strip, sixteen feet wide, on the street-car streets is not too much to devote to the daily transportation of the whole army of city workers.

The whole question of clear roadway and of stops is one of arithmetic and evolution. If the people in New York, Chicago and other large cities can give themselves a street-car service one-half more rapid and much more regular than they now enjoy, at no more expense than the discipline of their team traffic and an extra walk averaging about I5O feet, I think they will demand the better service. 